\title{
Dietary Diversity and Its Association with Anemia among Pregnant Women Attending Public Health Facilities in South Ethiopia Romedan Delil $^{1}$, Dessalegn Tamiru ${ }^{2 *}$, Beakal Zinab ${ }^{2}$
}

\author{
OPEN ACCESS \\ Citation: Romedan Delil, Dessalegn \\ Tamiru, Beakal Zinab. Dietary Diversity \\ and Its Association with Anemia among \\ Pregnant Women Attending Public \\ Health Facilities in Hossana Town, South \\ Ethiopia. Ethiop J Health Sci, \\ 2018;28(5):625. \\ doi:http://dx.doi.org/10.4314/ejhs.v28i5.14 \\ Received: December 29, 2017 \\ Accepted: January 3, 2018 \\ Published: September 1, 2018 \\ Copyright: (C) 2018 Remedan Delil, et al. \\ This is an open access article distributed \\ under the terms of the Creative Commons \\ Attribution License, which permits \\ unrestricted use, distribution, and \\ reproduction in any medium, provided the \\ original author and source are credited. \\ Funding: Nil \\ Competing Interests: The authors \\ declare that this manuscript was approved \\ by all authors in its form and that no \\ competing interest exists. \\ Affiliation and Correspondence: \\ ${ }^{1}$ Hossana Health Science College, \\ Hossana, Ethiopia \\ ${ }^{2}$ Jimma University, Department of \\ Population and Family Health, Jimma, \\ Ethiopia \\ *Email: dassalegn97@gmail.com
}

\section{ABSTRACT}

BACKGROUND: Anemia is a major public health problem among pregnant women in developing countries like Ethiopia. Nutritional deficiency related to anemia is an important contributor to maternal mortality and poor fetal outcomes.

METHODS: Institution based cross-sectional study was conducted among pregnant women to assess the prevalence of anemia and its association with dietary diversity in Hossana Town from March 15 to April 30, 2017. Systematic random sampling procedure was employed to select 314 study subjects. Data were collected using an interviewer administered semi-structured questionnaire supplemented with laboratory tests. Multivariable logistic regression was used to determine the independent predictors of anemia.

RESULTS: The prevalence of mild to moderate anemia among pregnant women was $56.6 \%$ and $40.8 \%$ respectively. The mean dietary diversity and food variety score of study participants were 7 and 22 respectively. Maternal education $(A O R=10.5 ; 95 \%$ CI:2.2, 27), occupation of spouse (AOR=9.3; 95\% CI:1.6, 53), nutrition education (AOR=2.5; 95\% CI:1.5, 6.4) and dietary diversity (AOR=18.6; 95\% CI: 4.4, 28) were significantly associated with anemia.

CONCLUSION: Anemia was found to be a moderate public health problem in Hossana Town. Therefore, there is a need of nutrition education and promotion awareness on healthy diets to prevent anemia among pregnant women.

KEYWORDS: Dietary Diversity, Food Variety, Anemia, Pregnant Women

\section{INTRODUCTION}

Anemia occurs at all stages of the life cycle but its risk is higher in state of pregnancy due to an increased iron necessity, physiological need, infections and blood loss. In spite of having diverse causes of anemia, nutritional deficiency is the prominent cause of anemia. High consumption of plant source diet as compared to animal source diet is common in Sub-Saharan countries, which is associated with a low intake of dietary iron. The intestinal absorption of any dietary iron is likely to be reduced as a result of the high intake of phytates from grains (1-3). 
Lack of diversified diets is a severe problem in the developing world, where diets are predominantly starchy staples with few animal products, seasonal fruits and vegetables. The nutritional status of a woman during pregnancy is important as a suboptimal diet impacts negatively on the health of the mother, the fetus and the newborn. Although Ethiopia has a wide range of agroclimatic conditions and grows a variety of cereals, root crops and vegetables, some of these are not fully utilized; there appears to be dependency on single food crops $(4,5)$. The value of a different diet has long been known, the high nutrient burdens of pregnancy put women of reproductive age in Ethiopia at high risk of anemia because consumption of low-quality, monotonous diets, poor traditional dietary practice of the society which depends on single staple food rather than diversified diet $(6,7)$.

Anemia is a global public health problem; it affects approximately 2 billion people worldwide and is estimated to contribute to more than 115,000 maternal deaths and 591, 000 prenatal deaths per year (8). Worldwide, the prevalence of anemia among pregnant women is $38.2 \%$, and 0.8 million pregnant women had severe anemia and it is associated with substantially worse mortality and cognitive and functional outcomes. The prevalence of anemia is varied across different regions of the world; the highest prevalence of anemia is recorded in Asia and African; the problem is very high and serious among women in developing countries. This reflects the high magnitude of factors affecting anemia such as iron deficiency, malaria and sickle cell anemia $(1,9)$.

The increment of anemia incidence among pregnant women indicates the need of revisions on national policies and public health strategies including improvements in dietary diversity, food fortification with iron, folic acid and control of infectious disease. Recognizing the complexity of anemia can lead to the establishment of effective strategies to control and prevent anemia $(3,10-12)$.

Anemia is a major public health problem in developing countries including Ethiopia. It causes different complications on the fetus and mother at the time of pregnancy. According to Ethiopia's demography health survey report, about onefourth of women aged 15-49 (23\%) are anemic with mild, moderate and severe anemia accounting for 17,5 and $1 \%$ respectively $(7,13)$. Poor nutritional status during pregnancy has adverse consequences which can persist from one generation to the next, since women who are undernourished are at risk of delivering premature or low birth weight infants, who are at risk of poor growth and development. Anaemia increases the risk of maternal and child mortality. There is an increased iron requirement during pregnancy due to greater expansion in plasma volume $(7,12,13)$.

In Hadiya Zone, the dietary pattern and its association with anemia among pregnant women was not known especially in public facilities. Furthermore, there are no studies on this topic at town and zonal levels. Hence, this study attempted to fill this gap by considering socio-economic and demographic factors.

\section{METHODS}

Study area and period: Institution based cross sectional study was conducted from March 15 to April 30, 2017 in Hossana Town public health facilities, Southern Ethiopia. Hossana Town is the capital of Hadiya Zone, and is located at $232 \mathrm{~km}$ to Southwest of Addis Ababa, Ethiopia. According to the 2014 census, the total population in Hossana was 101,849 . The estimated total households in the town were 20,785 , and women of childbearing age (15-49) were 23,731 . The main common foods of the population in the town were wheat and teff (12).

Source and study population: The source population was all pregnant women attending ANC in public health facilities in Hossana Town, Hadiya Zone, South Ethiopia. The study participants were selected pregnant women who were attending $\mathrm{ANC}$ at public health facilities of Hossana Town during the study period. Recently dewormed, severely ill and mentally disabled women were excluded from the study.

Sampling procedure and sample size: A total of 319 sample size was calculated by

DOI: http://dx.doi.org/10.4314/ejhs.v28i5.14 
using single population proportion formula with an expected prevalence of anemia, 62\% among pregnant women in Boditi town (14) with $5 \%$ margin of error at $95 \%$ confidence level. The desired sample size was calculated using the correction factor formula because the source population was less 10,000 .

Four public health facilities composed of one hospital and three health centers were included into the study and the desired numbers of study participants were allocated proportionally to each health facilities. Based on the number of attendants at each facility, the study participants were proportionally selected from all facilities. To select each study participant from each facility, we used registration book as sampling frame to select participants using systematic random sampling procedure. The attendance which contained the list of pregnant women was sought with the reference of three months period as the sampling frame.

Data collection methods: Socio-economic factors, maternal and clinical characteristics and dietary intake information were collected from all selected participants using pre-tested semi-structured questionnaires.The blood sample was collected by Hem Cue ${ }^{\circledR} 301$ system. The blood sample was collected into a special single-use micro cuvette whose walls were lined with the dry sodium deoxycholate reagents. The sample was tested by a medical laboratory technician to identify the hemoglobin level of study participants; stool examination was also done to identify intestinal parasites among studied women. Data were collected using pretested questionnaires. The questionnaire was prepared in English and translated into Amharic and Hadissa. Then, it was translated back to English to keep language consistency. Data analysis: Data were cleaned and checked for consistencies and completeness. Data were entered into EpiData version 3.5.1 and exported to SPSS version 20 for analysis. Descriptive and binary logistic regression analyses were done to see the association between the dependent and explanatory variables. In bivariate analysis, variables which had statistically significant results ( $p$-value $<0.25$ ) were entered into multivariable logistic regression model to identify the independent effect of each explanatory variable on the outcome variable. The strength of statistical association was measured by adjusted odd ratio with $95 \%$ of confidence interval and p-values less than 0.05 were considered as having statistically significant association with anemia.

The dietary diversity was defined as the number of food groups consumed over one week out of ten food groups before the survey. Pregnant women were coded as a consumer of a food item if they had consumed the food item at least once per week from the listed food which is locally available. Consumption of a food item over the reference period was given a score of "1" while non-consumption was given a score " 0 ". Since there was no conventional cut-off point to indicate adequate or inadequate dietary diversity within a week for the pregnant women, to calculate the highest dietary diversity score, the score was converted into tertiles. The higher tertile of the score was taken as high dietary diversity score and low tertiles was considered as minimum dietary diversity score. Nutrition education was defined as ever attending about women nutrition during pregnancy or lactation.

Ethical consideration: Ethical clearance and permission were obtained from the Research Review Board of Jimma University and offered to Hossana Town Health Bureau and respective administrative officials. Information about the objective of the study, confidentiality, autonomy and justice were explained for the participants during data collection. Informed verbal consent was obtained from each study participant.

\section{RESULTS}

A total of 314 participants were included into this study with $98.4 \%$ response rate. The mean age of

DOI: http://dx.doi.org/10.4314/ejhs.v28i5.14 
the study participants was $26.7 \pm 3.98$. The majority (97.1\%) of the respondents were married. Around two-third (68.5\%) of women were housewives. The majority (77\%) of them delivered at health facility. Nearly half of the respondents $(48.1 \%)$ had one or two antenatal care visits (Table 1).

Table 1: Socio-demographic and Economic Characteristics of the Study Participants in Hossana Town, South Ethiopia, 2017.

\begin{tabular}{|c|c|c|c|}
\hline Characteristics & Categories & Frequency & Percent \\
\hline \multirow[t]{4}{*}{ Age group } & $15-19$ & 2 & 0.6 \\
\hline & $20-24$ & 92 & 29.3 \\
\hline & $25-29$ & 158 & 50.3 \\
\hline & $\geq 30$ & 62 & 19.8 \\
\hline \multirow[t]{2}{*}{ Marital status } & Married & 305 & 97.1 \\
\hline & Non-married & 9 & 2.9 \\
\hline \multirow[t]{5}{*}{ Ethnicity } & Hadiya & 217 & 69.1 \\
\hline & Kambata & 53 & 16.9 \\
\hline & Silti & 12 & 3.8 \\
\hline & Amhara & 18 & 5.7 \\
\hline & Gurage & 14 & 4.5 \\
\hline \multirow{5}{*}{ Religion } & Orthodox & 21 & 6.7 \\
\hline & Protestant & 263 & 83.7 \\
\hline & Catholic & 2 & 0.6 \\
\hline & Muslim & 25 & 8 \\
\hline & Adventist & 3 & 1 \\
\hline \multirow{3}{*}{ Maternal education } & Can't read and write & 85 & 27.1 \\
\hline & Primary level & 124 & 39.5 \\
\hline & Secondary and above & 105 & 33.4 \\
\hline \multirow[t]{5}{*}{ Mothers' occupation } & House wife & 215 & 68.5 \\
\hline & Merchant & 32 & 10.2 \\
\hline & Government employee & 49 & 15.6 \\
\hline & Students & 18 & 5.7 \\
\hline & Government employee & 89 & 28.3 \\
\hline \multirow{3}{*}{ Spouse occupation } & Farmer & 29 & 9.2 \\
\hline & Merchant & 150 & 47.8 \\
\hline & Daily laborer & 46 & 14.7 \\
\hline \multirow[t]{2}{*}{ Family size } & $<5$ & 270 & 86 \\
\hline & $\geq 5$ & 44 & 14 \\
\hline \multirow{3}{*}{ Household monthly income } & $<1000$ & 50 & 15.9 \\
\hline & $1000-3000$ & 78 & 24.8 \\
\hline & $>3000$ & 151 & 48.1 \\
\hline \multirow[t]{2}{*}{ Birth space } & $<2$ years & 155 & 49.4 \\
\hline & $\geq 2$ years & 159 & 50.6 \\
\hline \multirow[t]{2}{*}{ Number of pregnancy } & Primi-gravida & 72 & 22.9 \\
\hline & Multi-gravida & 242 & 77.1 \\
\hline \multirow[t]{2}{*}{ Place of previous delivery } & Home & 53 & 16.9 \\
\hline & Health institution & 189 & 77 \\
\hline \multirow[t]{3}{*}{ Number of ANC visit } & 1-2 times & 151 & 48.1 \\
\hline & 3 times & 144 & 45.9 \\
\hline & 4 times & 19 & 6 \\
\hline \multirow[t]{2}{*}{ Ever utilized contraceptive } & Yes & 223 & 71 \\
\hline & No & 91 & 29 \\
\hline
\end{tabular}

DOI: http://dx.doi.org/10.4314/ejhs.v28i5.14 
Table 2: Food Groups Consumption Patterns of Pregnant Women in Public Health Facilities in Hossana Town, South Ethiopia, 2017.

\begin{tabular}{|c|c|c|c|}
\hline \multicolumn{2}{|l|}{ Food groups } & Frequency & Percent \\
\hline \multicolumn{2}{|l|}{ Milk and milk product } & 181 & 57.5 \\
\hline \multicolumn{2}{|l|}{ Egg } & 129 & 41.1 \\
\hline \multicolumn{2}{|l|}{ Cereals } & 312 & 99.4 \\
\hline \multicolumn{2}{|c|}{ Dark green leafy vegetables } & 305 & 97.1 \\
\hline \multicolumn{2}{|c|}{ Other vitamin A rich fruit, tubers and vegetables } & 260 & 82.5 \\
\hline \multicolumn{2}{|l|}{ Other fruits } & 262 & 83.4 \\
\hline \multicolumn{2}{|l|}{ Other vegetables } & 309 & 98.1 \\
\hline \multicolumn{2}{|l|}{ Meat, poultry and fish } & 153 & 48.7 \\
\hline \multicolumn{2}{|l|}{ Nut and seeds } & 19 & 6.1 \\
\hline \multicolumn{2}{|l|}{ Pulse or Legumes } & 311 & 99 \\
\hline \multirow[t]{3}{*}{ Dietary Diversity Score } & High & 70 & 22.3 \\
\hline & Medium & 168 & 53.5 \\
\hline & Low & 76 & 24.2 \\
\hline \multirow[t]{4}{*}{ Food Variety Score } & $<20$ & 103 & 32.8 \\
\hline & $20-24$ & 109 & 34.7 \\
\hline & $25-29$ & 92 & 29.3 \\
\hline & $\geq 30$ & 10 & 3.2 \\
\hline
\end{tabular}

The mean dietary intake of respondents was $3.6 \pm$ 2.27. More than one-fifth $(22.3 \%)$ of the participants consumed equal to or greater than eight food groups while 76(24.2\%) consumed minimum dietary diversity score or less than six food groups. A large proportion of study participants $(99.4 \%)$ consumed cereal products. More than half $(57.6 \%)$ of the pregnant women consumed milk and milk products while $48.7 \%$ of women consumed meat, poultry and fish (Table 2).

The mean food variety score of the respondents was $22.23 \pm 4.54$. The majority of study participants consumed cereal products like teff $(99.7 \%)$ and wheat (96.5\%). Proportionally, a small number of women consumed animal products like butter (27.1\%), meat (17.5\%), poultry $(1.3 \%)$ and fish $(0.6 \%)$ (Table 3$)$.

The overall prevalence of mild, moderate and severe anemia among pregnant women attending antenatal care at public health facilities in Hossana was $13.7 \%, 9.9 \%, 0.6 \%$, respectively. The total prevalence of anemia was $24.2 \%$ (95\% CI: 19.4 , 28.7) which is found to be a moderate public health significance (Figure 1). The Findings of this study showed a large number of study participants $(90.2 \%)$ were low dietary diversity consumers (Figure 2).
Table 3: Food Varieties Consumption Patterns of Pregnant Women in Public Health Facilities in Hossana Town, South Ethiopia, 2017.

\begin{tabular}{|c|c|c|}
\hline Food Varieties & Frequency & Percent \\
\hline Whole milk & 156 & 49.8 \\
\hline Cheese & 141 & 44.9 \\
\hline Yoghurt & 94 & 29.9 \\
\hline Butter & 85 & 27.1 \\
\hline Wheat & 303 & 96.5 \\
\hline Barley & 252 & 80.5 \\
\hline Oats & 44 & 14 \\
\hline rice & 203 & 64.6 \\
\hline teff & 313 & 99.7 \\
\hline Millet & 14 & 4.5 \\
\hline Potato & 292 & 93 \\
\hline kale & 249 & 79.3 \\
\hline Swiss chard & 36 & 11.5 \\
\hline Endive & 267 & 85 \\
\hline Lettuce & 185 & 58.9 \\
\hline Mango & 213 & 67.8 \\
\hline Papaya & 154 & 49 \\
\hline Orange & 144 & 45.9 \\
\hline Lemon & 219 & 69.7 \\
\hline Tomato & 284 & 90.4 \\
\hline Chillies & 215 & 68.5 \\
\hline Beef & 102 & 32.5 \\
\hline Mutton & 55 & 17.5 \\
\hline Goat & 41 & 13.1 \\
\hline poultry & 4 & 1.3 \\
\hline Fish & 2 & 0.6 \\
\hline Peas & 287 & 91.4 \\
\hline Chickpeas & 143 & 45.5 \\
\hline Horse bean & 85 & 27.1 \\
\hline Lentils & 298 & 94.9 \\
\hline Kidney bean & 8 & 2.5 \\
\hline Product of Enset & 269 & 86.2 \\
\hline
\end{tabular}

DOI: http://dx.doi.org/10.4314/ejhs.v28i5.14 


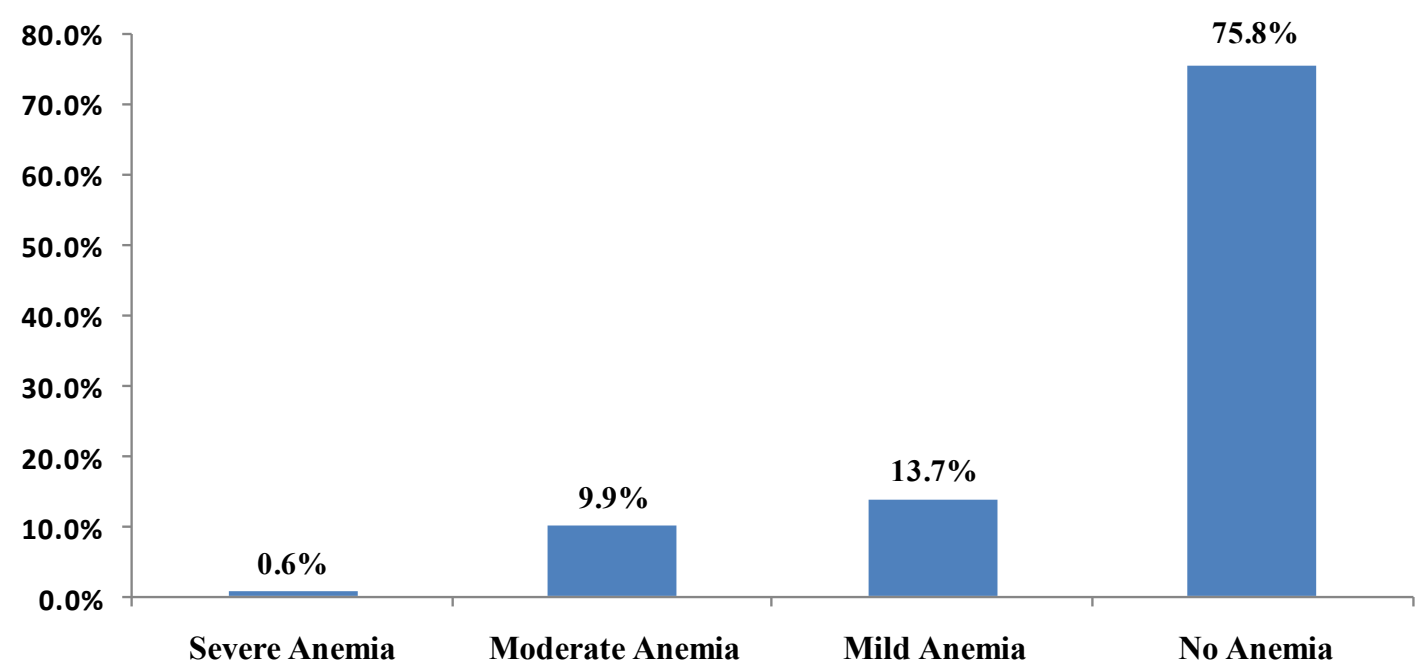

Figure 1: The severity of anemia among pregnant women in public health facilities of Hossana town, South Ethiopia, 2017

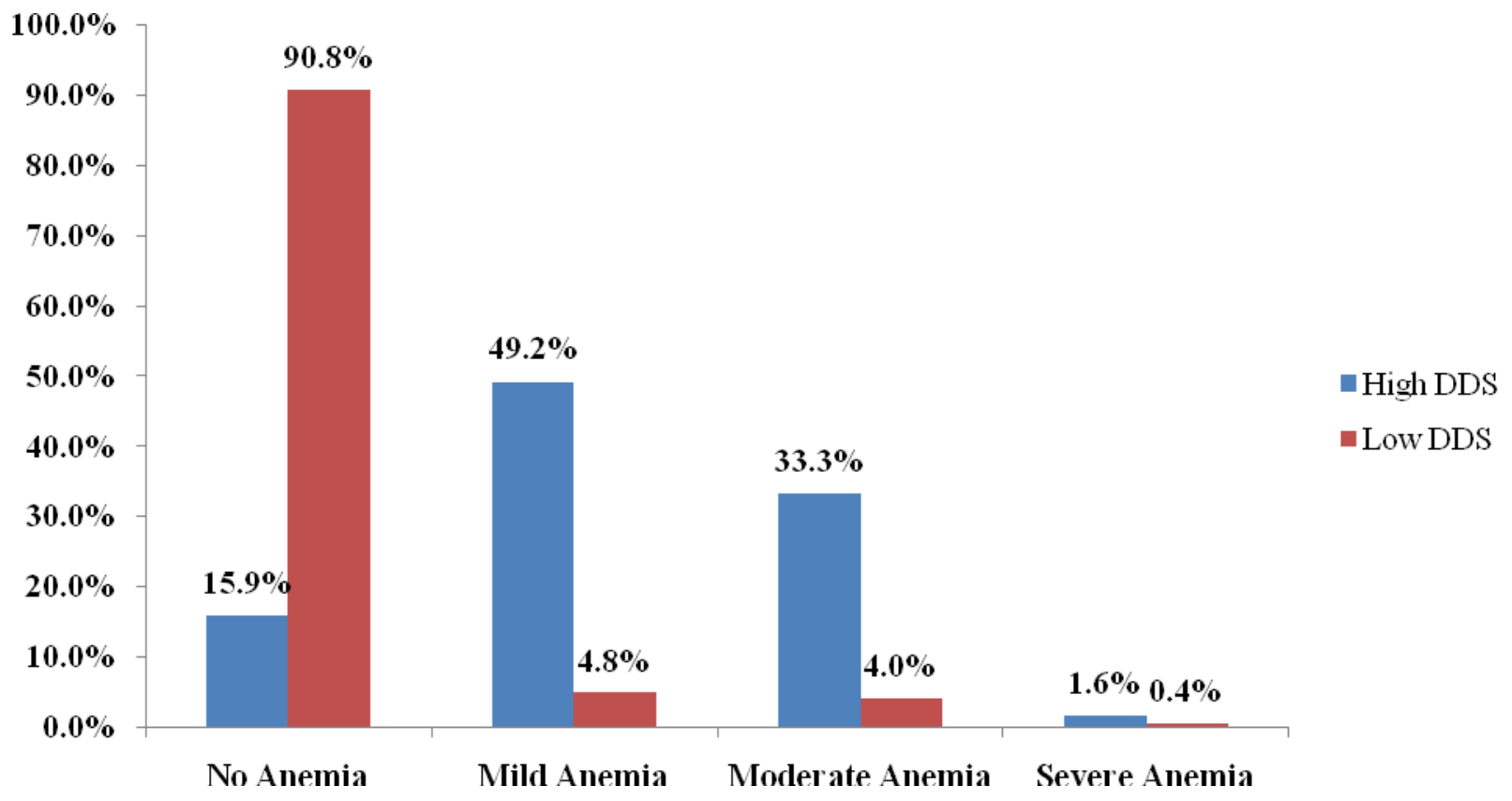

Figure 2: Food groups with Anemia Prevalence among Pregnant Women in Public Health Facilities in Hossana town, South Ethiopia, 2017 
Table 4: Factors Associated with Anemia among Pregnant Women Attending Public Health Facilities in Hossana Town, South Ethiopia, 2017.

\begin{tabular}{|c|c|c|c|c|c|}
\hline \multirow[b]{2}{*}{ Characteristics } & \multirow[b]{2}{*}{ Category } & \multicolumn{2}{|l|}{ Anemic } & \multirow[b]{2}{*}{$\operatorname{COR}(95 \% \mathrm{CI})$} & \multirow[b]{2}{*}{$\operatorname{AOR}(95 \% \mathrm{CI})$} \\
\hline & & Yes $(\%)$ & No $(\%)$ & & \\
\hline \multirow{3}{*}{ Mothers' education } & Can't read and write & $31(36.5)$ & $54(63.5)$ & $16(3.3,77)^{* *}$ & $10.5(2.2,27)^{* *}$ \\
\hline & Primary level & $27(21.8)$ & $97(78.2)$ & $5.1(1.6,16.2)^{* *}$ & $8.9(1.6,51)^{* *}$ \\
\hline & Secondary and above & $18(17.1)$ & $87(82.9)$ & 1 & 1 \\
\hline \multirow{3}{*}{ Spouse education } & Can't read and write & $26(72.2)$ & $10(27.8)$ & $4.4(0.18,16.1)$ & $9.7(0.03,5.1)$ \\
\hline & Primary level & $32(35.2)$ & $59(64.8)$ & $3.23(1.3,22.5)$ & $0.3(0.02,6)$. \\
\hline & Secondary and above & $18(9.6)$ & $72(90.4)$ & 1 & 1 \\
\hline \multirow[t]{4}{*}{ Mothers' occupation } & House wife & $28(12.4)$ & $196(77.6)$ & 1 & 1 \\
\hline & Merchant & $20(62.5)$ & $12(37.5)$ & $1.7(0.6,5.2)$ & $0.6(0.12,3)$ \\
\hline & Government employee & $16(32.6)$ & $33(67.4)$ & $4.2(1.2,14)$ & $6.2(0.2,16)$ \\
\hline & Students & $12(66.7)$ & $6(33.3)$ & $2.6(0.3,21.9)$ & $0.9(0.6,7.1)$ \\
\hline \multirow[t]{4}{*}{ Spouse occupation } & Government employee & $14(15.7)$ & $75(84.3)$ & 1 & 1 \\
\hline & Farmer & $15(51.7)$ & $14(48.3)$ & $3.9(1.3,11.9)^{*}$ & $10.2(2.1,52)$ \\
\hline & Merchant & $20(13.3)$ & $130(86.7)$ & $1.5(1.4,5.9)^{*}$ & $4.8(1.03,22)$ \\
\hline & Daily laborer & $27(58.7)$ & $19(41.3)$ & $11.9(3.4,40.9)^{* *}$ & $9.3(1.6,53)^{* *}$ \\
\hline \multirow[t]{2}{*}{ Birth space } & $<24$ month & $45(29)$ & $110(71)$ & $1.7(1.4,3.2)$ & $1.6(0.7,3.7)$ \\
\hline & $\geq 24$ month & $31(19)$ & $128(81)$ & 1 & 1 \\
\hline \multirow[t]{3}{*}{ Household monthly income } & $<1000$ & $30(60)$ & $20(40)$ & $2.2(1.3,4.9)$ & $1.3(0.5,3.6)$ \\
\hline & $1000-3000$ & $17(21.8)$ & $61(78.2)$ & $0.7(0.3,1.7)$ & $0.6(0.2,1.9)$ \\
\hline & $>3000$ & $14(9.3)$ & $137(90.7)$ & 1 & 1 \\
\hline \multirow[t]{2}{*}{ History of malaria } & Yes & $12(48)$ & $13(52)$ & $3.2(1.03,11.9)$ & $0.2(0.02,3.3)$ \\
\hline & No & $64(22.1)$ & $225(77.9)$ & 1 & 1 \\
\hline \multirow[t]{2}{*}{ Heard about anemia } & Yes & $66(23.2)$ & $219(76.8)$ & $1.9(0.9,4.5)$ & $1.2(0.3,3.8)$ \\
\hline & No & $10(34.5)$ & $19(65.5)$ & 1 & 1 \\
\hline \multirow[t]{2}{*}{ Attend nutrition education } & Yes & $35(35)$ & $65(65)$ & 1 & 1 \\
\hline & No & $41(19.2)$ & $173(80.8)$ & $3.4(1.6,7.2)^{*}$ & $2.5(1.5,6.4)^{*}$ \\
\hline \multirow[t]{2}{*}{ Knowledge about Iron } & Yes & $13(40.6)$ & $19(59.4)$ & 1 & 1 \\
\hline & No & $63(22.3)$ & $219(77.7)$ & $2.7(0.8,9.3)$ & $1.2(0.2,6.7)$ \\
\hline \multirow[t]{2}{*}{ Dietary Diversity Score } & Low & $50(65.8)$ & $26(34.2)$ & $30.8(11.8,13)^{* *}$ & $18.6(4.4,28)^{* *}$ \\
\hline & High & $14(20)$ & $56(80)$ & 1 & 1 \\
\hline
\end{tabular}

*Significant at $<0.05,{ }^{*}$ Significant at $<0.0$ COR: Crude Odds Ratio, AOR: Adjusted Odds Ratio, CI: Confidence Interval 
The findings of bivariate analysis showed that both maternal and paternal education and occupation, birth space, information about anemia and nutrition, low family income and minimum dietary diversity score were identified as the candidate for multivariable logistic regression analysis. The Findings of multivariable logistic regression analysis showed that attending only primary school (AOR=8.9; CI: 1.6, 51), lack of education $(\mathrm{AOR}=10.5 ; 95 \% \mathrm{CI}: 2.2,27)$, having daily laborer spouse (AOR=9.3; 95\% CI: $1.6,53)$, lack of information about iron source foods (AOR $=2.5 ; 95 \% \mathrm{CI}: 1.5,6.4)$ and low dietary diversity score intake (AOR $=18.6$; 95\% CI: 4.4, 28) were positively associated with an exposure among pregnant women in Hossana Town public health facilities (Table 4).

\section{DISCUSSION}

Anemia was found to be a moderate public health problem which was consistent with the study from Gondar and Nekemt towns in which $23.2 \%$ and $29 \%$ of pregnant women were anemic respectively $(15,16)$. Studies also indicated that anemia is a major public health problem in developing countries including Ethiopia (17-21). According to Ethiopia's demography health survey report, about one-fourth of women aged from 15-49 (23\%) were anemic (21-23). However, this figure was low as compared to the findings from Northern Nigeria (61.2\%), Gilgel Gibe (53.9\%) and Wolayita Soddo Town (39.94\%) (1720). This inconsistency might be due to differences with respect to socio-economic status, geographic and eating habit of study participants.

Lack of education among pregnant women was identified as one of the contributors to anemia. Pregnant women who were not able to read and write were more exposed to anemia as compared to women who attended secondary school and above which was consistent with other findings $(2,18,24)$. This might be due to the fact that women who achieved secondary and above schooling had better awareness about balanced diet during pregnancy.
The occupation status of spouses was significantly associated with occurrence of anemia among pregnant women. Pregnant women whose spouses were daily laborers were more exposed to anemia as compared to women whose husbands were governmental employees which was consistent with studies from Turkey and Arba Minch town $(24,25)$. This might be due to the fact that the economic level of merchants and other employees were higher than daily laborers'. It also suggests that women in low socio-economic levels are likely to be poorly educated and regularly have financial constraints which is challenging to access and afford nutritious food. Hence, they are more likely to suffer from the adverse effects of poor/inadequate nutrition, chronic infections and worm infestations.

Attending health education about nutrition during pregnancy was significantly associated with anemia. Women who did not get health education about nutrition during antenatal care were more likely to be exposed to anemia as compared to those who attended nutrition education. This finding is consistent with a study conducted at Arba Minch Town (25). This similarity might be due to the current wide-open health education for pregnant women at health institutions.

Pregnant women who consumed low dietary diversity were more likely to be anemic as compared to women who ate high dietary diversity score. This finding was consistent with the studies done in Mekelle Town and in Ghana $(22,26)$. This might be due to the fact that pregnancy is the most nutritionally demanding period in a woman's life cycle. As a result, their iron level declined. Pregnant women are recommended to eat more diversified diet than monotonous diet to compensate the normal physiological demand of fetus and mother.

Although this study has a significant contribution to address the nutritional problem of pregnant women, there might be social desirability bias where participants demanded to provide dietary information on food frequency questionnaire and monthly income of the family. Additionally, most women consumed food from a

DOI: http://dx.doi.org/10.4314/ejhs.v28i5.14 
common bowl or mixed dish which is challenging to quantify specific intake food items. Quantitative measurement of nutrients was not done due to absence of dataset or measurement used to provide information on the amount of food consumed by pregnant women. The study was cross-sectional and may not show variations of dietary practices due to seasonal changes.

Generally, the findings of this study can have a significant implication for national nutrition strategy and the national nutrition program in the promotion women nutrition during the pregnancy. The prevalence of anemia among pregnant women was a moderate public health problem. The educational status of both pregnant women and their spouses, occupation status, health education during pregnancy and low minimum dietary diversity were significantly associated with anemia among the pregnant women in Hossana town. Therefore, adult learning should be strengthened to enhance women's educational level. There is also a need for enhancing dietary diversity or food groups and promotion of awareness on nutritional benefits especially consumption of iron-rich foods for pregnant women. Health extension workers should underline ongoing strengthening intervention strategies to decline the risk of anemia among pregnant women.

\section{REFERENCES}

1. Balarajan Y, Ramakrishnan U, Özaltin E, Shankar A, Subramanian S. Anaemia in low-income and middle-income countries. Lancet. 2011; 378(9809):2123-35.

2. Lindsay K, Gibney E, Mcauliffe F. Maternal nutrition among women from Sub-Saharan Africa with a focus on Nigeria and potential implications for pregnancy outcomes among immigrant populations in developed countries. J Hum Nutr Diet. 2012; 25:534-46.

3. Prakash S, Yadav K. Maternal Anemia in Pregnancy: An Overview. IjpprHuman. 2015; 4(3).

4. Masset E, Haddad L, Cornelius A, IsazaCastro J. Effectiveness of agricultural interventions that aim to improve nutritional status of children: systematic review. BMJ. 2012;344(7843): 8222.

5. Tamiru D, Argaw A, Gerbaba M, Nigussie A, Ayana G, Belachew T. Improving Dietary Diversity of School Adolescents through School Based Nutrition Education and Home Gardening in Jimma Zone: Quasi-Experimental Design. Eating Behaviors. 2016, 23: 18086.

6. Central Statistical Agency(CSA). Ethiopia Mini Demographic and Health Survey. Ethiopia; 2014. https://www.unicef.org/ethiopia/Mini_DH S_2014_Final_Report.pdf

7. Central Statistical Agency(CSA). Ethiopia Demographic and Health Survey. Addis Ababa, Ethiopia; 2012. https://www.unicef. org/ethiopia/ET_2011_EDHS.pdf

8. WHO. The Global Prevalence Of Anaemia In 2011. Geneva, Switherland. www.who.int/nutrition/publications/.../glob al_prevalence_anaemia_2011/en/

9. WHO. Worldwide prevalence of anaemia. Geneva, Switherland; 2005. whqlibdoc. who.int/publications/2008/9789241596657 eng.pdf

10. WHO. Essential Nutrition Actions: improving maternal \& newborn, infant and young child health and nutrition. Geneva, Switherland; 2013. www.who.int/nutrition/ publications/infantfeeding/essential_nutriti on_actions $/ \mathrm{en} / \% 0 \mathrm{~A}$

11. Central Statistical Agency(CSA). Ethiopia Demographic and Health Survey. Geneva, Switherland; 2016. https://dhsprogram. com/pubs/pdf/FR328/FR328.pdf

12. Population Reference Bureau (PRB). Ethiopia Demographic and Health Survey 2005. www.prb.org/ethiopiademographic andhealthsurvey2005/

13. Hall A, Kassa T, Demissie T, Degefie T, Lee S. National survey of the health and nutrition of schoolchildren in Ethiopia. Trop Med Int Heal. 2008;13(12):1518-26.

14. Lelissa D, Yilma M, Shewalem W, Abraha A, Worku M, Ambachew $\mathrm{H}$, et al.

DOI: http://dx.doi.org/10.4314/ejhs.v28i5.14 
Prevalence of Anemia Among Women Receiving Antenatal Care at Boditii Health Center, Southern Ethiopia. Clinical Medicine Research. 2015;4(3):79-86.

15. Melku M, Addis Z, Alem M, Enawgaw B. Prevalence and Predictors of Maternal Anemia during Pregnancy in Gondar , Northwest Ethiopia: An Institutional Based Cross-Sectional Study. Hindawi Publ Corp. 2014;2014.

16. Ejeta E, Alemnew B, Fikadu A, Fikadu M, Tesfaye L, Birhanu T. Prevalence of Anaemia in Pregnant Womens and Associated Risk Factors in Western Ethiopia. Food Sci Qual Manag. 2014;31(6).

17. Oladipo A, Falana A, Adegoke F, Sambo A. Prevalence of Anemia among Pregnant Women and its Determinants in Northern Nigeria. Eur $J$ Nutr Food Saf. 2015;5(5):865-6.

18. Getachew M, Yewhalaw D, Tafess K, Getachew Y, Zeynudin A. Anaemia and associated risk factors among pregnant women in Gilgel Gibe dam area, Southwest Ethiopia. Parasit Vectors. 2012;5(296):1-8.

19. Lealem G, Town W. Original Article Anemia And Associated Factors Among Pregnant Women Attending Antenatal Care Clinic In Wolayita Sodo Town, Southern Ethiopia. Ethiop J Heal Sci. 2015;25(2): 10-5.

20. Esmat M, Mohammad M, Behnam S, Shahrzad M, Soodabeh T, Minoo A. Prevalence of Iron Deficiency Anemia among Iranian Pregnant Women; a Systematic Review and Meta-analysis. $J$ Reprod Infertil. 2010;11(1):17-24.

21. Victor R, Baines S, Agho K, Dibley M. Factors associated with inappropriate complementary feeding practices among children aged 6-23 months in Tanzania. Matern Child Nutr. 2012;10(4):1-17.

22. Abriha A, Yesuf M, Wassie M. Prevalence and associated factors of anemia among pregnant women of Mekelle town: a cross sectional study. BMC Res Notes. 2014;7(888):1-6.

23. Gies S, Brabin B, Yassin M, Cuevas L. Comparison of screening methods for anaemia in pregnant women in Awassa, Ethiopia. Trop Med Int Health. 2003; 8(4):301-9.

24. Karaoglu L, Pehlivan E, Egri M, Deprem $\mathrm{C}$, Gunes $\mathrm{G}$, Genc M, et al. The prevalence of nutritional anemia in pregnancy in an east Anatolian province, Turkey. $B M C$ Public Health. 2010;10(329):1-12.

25. Bekele A, Tilahun M, Mekuria A. Prevalence of Anemia and Its Associated Factors among Pregnant Women Attending Antenatal Care in Health Institutions of Arba Minch Town, Gamo Gofa Zone , Ethiopia: A Cross-Sectional Study. Hindawi Publ Corp. 2016;2016:1-9.

26. Saaka M, Abdul A. Role of dietary diversity in ensuring adequate heamatological status during pregnancy. Int J Med Res Health Sci. 2015;4(4): 749-55. 